\title{
Evaluation of the different thresholding strategies for quantifying choriocapillaris using optical coherence tomography angiography
}

\author{
Rita Laiginhas $^{1,2} \wedge$, Diogo Cabral $^{3,4}$, Manuel Falcão ${ }^{5,6}$ \\ ${ }^{1}$ Department of Ophthalmology, CHEDV, Portugal; ${ }^{2}$ PDICSS, Faculty of Medicine of the University of Porto, Porto, Portugal; ${ }^{3}$ CEDOC, NOVA \\ Medical School I Faculdade de Ciências Médicas, Universidade NOVA de Lisboa, Lisbon, Portugal; ${ }^{4}$ Instituto de Oftalmologia Dr. Gama Pinto, \\ Lisboa, Portugal; ${ }^{5}$ Department of Ophthalmology, Centro Hospitalar e Universitário de São João, Porto, Portugal; ${ }^{6}$ Department of Surgery and \\ Physiology, Faculty of Medicine of the University of Porto, Porto, Portugal
}

Correspondence to: Rita Laiginhas, MD. PDICSS, Faculty of Medicine of the University of Porto, 4200-319 Porto, Portugal.

Email: ritalaiginhas@gmail.com.

Background: In this paper, we evaluate the different thresholding strategies that have been used for the quantification of the choriocapillaris (CC) and explore their repeatability and the interchangeability of the measurements resulting from its application.

Methods: Observational study. Eighteen eyes from nine healthy volunteers aged $>18$ years were imaged four consecutive times with a SD-OCTA system (Heidelberg Engineering, Germany) using a $10^{\circ} \times 10^{\circ}$ highresolution protocol centered on the fovea. Projection artifacts were removed, and the $\mathrm{CC}$ was bracketed between 10 and $30 \mu \mathrm{m}$ below Bruch's membrane. For the quantification of CC, we used four flow deficits (FD) parameters: FD number, mean FD size, total FD area and FD density. We performed a systematic review of literature to collect the thresholding methods that have been used for the quantification of CC. The CC quantification parameters were then evaluated after applying each of the thresholding strategies. Intraclass correlation coefficient (ICC) and Pearson's correlation analysis were used to compare the repeatability and interchangeability among the different thresholding strategies for quantifying the CC.

Results: A total of 72 optical coherence tomography angiography (OCTA) examinations were considered. The systematic review allowed us to conclude that three local thresholding strategies (Phansalkar, mean and Niblack) and three global thresholding strategies (mean, default, Otsu) have been used for CC quantification. These strategies were evaluated in our observational study. We found a high agreement within the same method in the quantification of FD number, mean FD size, total FD area and FD density but a poor agreement with different strategies. Local strategies achieved a significantly superior ICC than global ones in CC quantification.

Conclusions: In conclusion, the interchangeability of the CC quantification using different thresholding strategies is low, and direct comparisons should not be performed. Local thresholding strategies are significantly superior to global ones for quantifying CC and should be preferred. There is an unmet need for a uniform strategy to quantify CC in future studies.

Keywords: Binarization; choriocapillaris (CC); optical coherence tomography angiography (OCTA); thresholding

Submitted Feb 22, 2020. Accepted for publication Jul 03, 2020.

doi: 10.21037/qims-20-340

View this article at: http://dx.doi.org/10.21037/qims-20-340

^ORCID: 0000-0001-7275-6470. 


\section{Introduction}

The choriocapillaris (CC) is a dense vascular layer that is located beneath Bruch's membrane and provides metabolic support for the outer retina, retinal pigmented epithelium and choroidal stroma (1). The study of CC properties and morphology has been of interest throughout the years as histopathological studies revealed that the CC plays an important role in prevalent retinal and choroidal diseases (2-4). However, quantitative studies of the CC have been limited by its in-vivo inaccessibility $(5,6)$.

Recently, optical coherence tomography angiography (OCTA) emerged as means of providing detailed images of retinal vasculature. Currently available OCTA devices are capable of generating high-quality en-face images of the retinal plexuses that enable retinal vasculature quantification (7). Such ability of resolving the microvascular networks of the retina is possible as the inter-capillary distance of the vessels in these plexuses $(71.3 \pm 5.2 \mu \mathrm{m})(8)$ are generally larger than the lateral resolution of the system $(15-20 \mu \mathrm{m})(9)$. Particularly for research purposes, the ability to reproducibly and objectively quantify OCTA scans is critical as it allows images to be compared. Not all OCTA instruments have built-in software to calculate the vasculature metrics. As such, researchers and clinicians currently face the challenges of exploring quantification methodologies on en-face OCTA exported images (10-12). The process of OCTA image quantification requires the application of a thresholding strategy (in other words, a process that enables the separation of the region of interest from the background) (13). The output of the thresholding operation is a binary image, where the foreground and the background are represented by white or black pixels, according to a pre-definition. Different thresholding strategies have been described by researchers, most of them based on the use of open-source software, such as Image J (National Institutes of Health, Bethesda, available at https://imagej.nih.gov/ij/) (14).

Currently, there are no clear consensus on the best thresholding strategy for the binarization of CC images and multiple strategies have been reported. With OCTA quantification becoming increasingly common among researchers, there is a pressing need to understand how different methodologies can affect metrics. It is also important to understand how well different methods perform in both producing accurate metrics and minimizing variability. To our knowledge, few studies have reported the reproducibility and reliability of the different thresholding strategies for the quantification of CC vasculature in OCTA.

The aim of our work is to evaluate the repeatability of the different thresholding strategies that have been used for the quantification of CC as well as to evaluate how the CC images are affected by the application of different thresholding strategies.

\section{Methods}

\section{Systematic review}

We conducted a systematic review and comprehensive search to identify the thresholding strategies that have been applied for the purpose of CC quantification in OCTA scans.

\section{Terminology}

For the purpose of this paper, the following terminology was used:

(I) CC: the capillary plexus of the choroid located between the Sattler's layer and Bruch's membrane. For the purpose of this review, we considered the OCTA slab defined by the authors in each study.

(II) Thresholding strategy: this term is used to refer to the strategy that was applied in raw greyscale CC scans to convert them into binary images (separate the region of interest from the background).

\section{Search strategy}

We conducted a systematic review from 1st January 2014 to 31st December 2019 using the PubMed electronic database. We've used the following query: "(choriocapillaris AND [(optical coherence tomography angiography) OR (OCTA) OR (OCT angiography)]". We opted to include a broad query so that we could encompass the larger number of studies possible.

\section{Eligibility criteria}

We only included studies that reported macular CC vascular quantification strategies in OCTA images in humans (either as flow voids/deficits or as vascular density or similar concepts). Identified publications were screened manually based on the title and abstract. We placed no restrictions or limits during the search process (language, time or country of origin).

\section{Data extraction and synthesis}

After excluding publications that did not analyze 
quantitatively CC OCTA macular scans, we then manually searched on the manuscripts and the thresholding strategy that had been used was collected.

\section{Observational study}

A prospective study was performed at Centro Hospitalar de Entre o Douro e Vouga (Portugal). The study was approved by the Institutional Ethics Committee of Centro Hospitalar de Entre o Douro e Vouga (No. CA-0708/18-0t_MP/AC) and adhered to the tenets of the Declaration of Helsinki and its later amendments. Informed consent was obtained from participants before the inclusion in the study.

\section{Sample}

Eighteen eyes from nine healthy individuals $>18$ years $(8$ females, mean age of $38.2 \pm 11.4$ years) with no systemic or ocular history, no visual complaints, and no identified optic disc, retinal or choroidal pathologies on examination and a refractive error $<6.00$ diopters were enrolled in the study.

\section{Image acquisition}

The individuals were scanned in both eyes using a $10^{\circ} \times 10^{\circ}$ scan high-resolution protocol centered on the fovea with the Heidelberg Spectralis OCTA system (version 1.10.2.0, Spectralis; Heidelberg Engineering, Heidelberg, Germany). The device uses an $870 \mu \mathrm{m}$ central wavelength and images at 85,000 per second with an isotropic lateral resolution of $5.7 \mu \mathrm{m} /$ pixel. The image cubes were acquired using 5 repeated scans with the TruTrack technology from Heidelberg. The imaging protocol was explained to the participants before any acquisition. For evaluating repeatability, we performed four consecutive OCTA acquisitions in each eye, separated by a few seconds. Images were manually reviewed, and lowquality scans were excluded (scans with motion, projection or other image artifacts). All images were obtained by the same trained ophthalmic professional and in the same environment conditions. Acquisitions were repeated if necessary, to obtain high-quality images.

\section{Image processing}

Automated segmentation of the CC was performed using the software provided within the Spectralis ${ }^{\circledR}$ (Heidelberg Engineering). The boundary of the CC slab is defined 10$30 \mu \mathrm{m}$ below the Bruch's membrane. The retinal projection artifacts were removed using the projection artifact removal tool from Heidelberg (Software version 6.14.1) before the images were further processed for quantification. The algorithm removes flow projection from the normally avascular outer retinal slab and preserves in situ flow signal of the deeper vessels. The angiograms were exported for analysis as Tagged Image File Format (tiff) format. Image analysis was performed using Image J V. 1.51 (National Institutes of Health, Bethesda) (14). Raw data was cut using the same frame $(960 \times 960$ pixels) in order to exclude artifacts that sometimes occur in the margin of the scan. Brightness and contrast adjustments were not performed, the images were manipulated in the native form. Before any conversion, the initial pixel values were coded as 8 -bit values, ranging from 0-255.

\section{Histogram analysis}

For analysis purpose, we extracted the images histograms of each CC image to verify if different eyes followed similar distributions. Histogram analysis was performed using Image J V. 1.51 (National Institutes of Health, Bethesda) (14).

\section{Image post-processing}

Following the mentioned transformations, each CC angiogram was then processed with all of the thresholding strategies found in the initial systematic review using Image J V. 1.51 (National Institutes of Health, Bethesda) (14).

\section{Quantification parameters}

Contrasting to the retinal plexuses, the CC is a much denser vascular network $(15,16)$ with a much smaller inter-capillary distance [average 10-25 $\mu \mathrm{m}$ (17)] that cannot be resolved by OCTA devices. Thus, a different approach is necessary for quantification purposes. This limitation has been resolved by the quantification of the flow deficits (FD) in the exported CC images (18-26). FD are defined as regions of non-perfusion or low perfusion, where the flow is below the sensitivity limit of the current OCTA technology (19). In a binary image of the CC, FD correspond to black pixels or the background. In our study, to quantify the FD, images were processed with the 'Analyze Particles' command (Image J V. 1.51, National Institutes of Health, Bethesda) (14). This function retrieved the following measurements: (I) the FD number, (II) mean FD size, (III) total FD area and (IV) FD density. These variables were represented using box blots to allow the visualization the quantitative distribution of the values according to the thresholding strategy.

\section{Reproducibility of CC FD quantification}

We evaluated the reproducibility of CC FD quantification for each thresholding strategy found in the systematic 
review. This was performed using the four consecutive scans from the same eye, acquired in the same environmental conditions, as previously described. After applying the same thresholding strategy to the four scans per eye, we calculated the FD number, the mean FD size, the total FD area and the FD density for each scan. The repeatability of the CC FD quantification for each strategy was then estimated using the intraclass correlation coefficient (ICC) and the respective $95 \%$ confidence interval (CI), with the two-way mixed, single measures, absolute agreement mode. All statistical analysis was performed using IBM SPSS Statistics v. 25 (SPSS Inc., Chicago, IL, USA). Significance was set at 0.05 .

\section{Agreement among the strategies for $\mathrm{CC}$ quantification}

For this purpose, the first CC scan of each eye was used. We first evaluated the correlation among the same FD quantification parameters after applying the different thresholding strategies to verify if the algorithms retrieved similar trends in values variation. Correlation among the different obtained values using different strategies was evaluated using the Pearson's correlation coefficient (both $\mathrm{r}$ values and $\mathrm{P}$ values are reported). In the absence of correlation, either the thresholding strategies had a complete absolute agreement, either they fail in retrieving FD. We then tested the absolute agreement for the different thresholding strategies for measuring the same scan and evaluated the correlation between the different parameters of FD obtained using different thresholding strategies. The agreement among the different thresholding strategies for quantifying FD in the same CC scan was evaluated using the ICC and the respective $95 \% \mathrm{CI}$, as previously described. All statistical analysis was performed using IBM SPSS Statistics v. 25 (SPSS Inc., Chicago, IL, USA). Significance was set at 0.05 .

\section{Results}

\section{Systematic review}

Figure $S 1$ presents the search strategy and its results. One thousand six hundred and seventy-four studies were identified by the query. From these, 1,490 were excluded after a primary screening. From the remaining 184 studies, 51 were excluded as they did not meet the inclusion criteria. One hundred and thirty-three studies were included in the final synthesis. The detailed results are summarized in Table S1. We grouped the found thresholding strategies in major categories as:

(I) OCTA device-related thresholding strategies $(n=40)$ : studies that used the thresholding method that is intrinsic to the OCTA device. These algorithms are not customizable and are devicedependent and thus were not considered for the observational study.

(II) Thresholding strategies customized by the author $(\mathrm{n}=37)$ : studies that used customized thresholding strategies designed by the authors. These strategies were not included in the observational study.

(III) Unknown/inaccessible $(\mathrm{n}=5)$ : studies in which the thresholding strategy was not accessible, and authors did not answer to direct email questioning. These strategies were not included in the observational study.

(IV) Global thresholding strategies $(\mathrm{n}=25)$ : the simplest form of binarization uses global thresholds. These methods employ a threshold value, $t$, pixel values greater that $t$ are set to 1 and pixel values smaller or equal to $t$ are set to 0 , or vice versa (27-30). Image histogram (the representation of the number of pixels in an image as a function of their intensity) computing is an important tool in the decision for global thresholding methods and values (30). In an ideal case, the histogram has a deep and sharp valley between two peaks representing objects and background, respectively, so that the threshold can be chosen at the bottom of this valley. As a single threshold is applied to the entire image, these methods produce incompetent binarization in conditions as the presence of noise or uneven background. Three global thresholding strategies have been used to quantify CC OCTA scans according to our review and were evaluated in the observational study: global Otsu, global mean and global default. The definition of each algorithm is presented as a Supplementary file 1 .

(V) Local thresholding strategies $(n=32)$ : local binarization methods were created to surpass the limitations of global methods as they assign different threshold values according to local properties of the image (28). Various factors, such as nonstationary and correlated noise, ambient illumination, busyness of gray levels within the object and its background, inadequate contrast, and object size not commensurate with the scene, complicate the thresholding operation. Thus, 


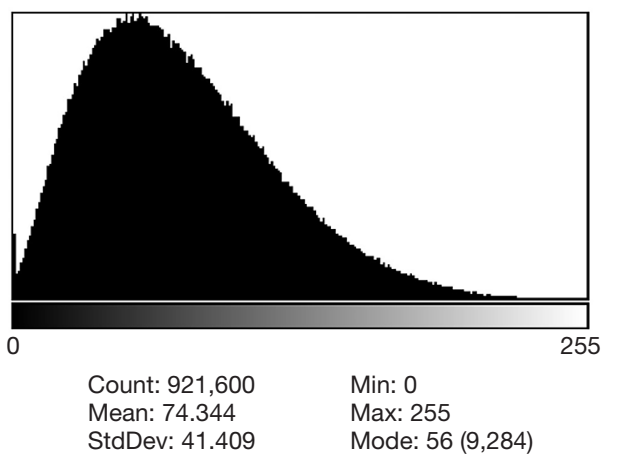

Figure 1 The figure illustrates the histogram from one of the CC exported images after 8-bit conversion. Analysis was performed using Image J V. 1.51 (National Institutes of Health, Bethesda). CC, choriocapillaris.

the ideal method must be selected case by case, depending on the image properties. Three local thresholding strategies have been used to quantify CC OCTA scans according to our review and were evaluated in the observational study: local Phalsankar, local mean/median and local Niblack. The definition of each algorithm is presented as a Supplementary file 1 .

\section{Observational study}

In the following paragraphs we present the results of CC scans analysis using the three global (global Otsu, global mean and global default) and the three local (local Phalsankar, local mean/median and local Niblack) thresholding strategies obtained in the systematic review.

\section{Histogram analysis}

A typical histogram from the en-face CC images after 8-bit conversion is demonstrated in Figure 1 as an example. Inspection of the histogram showed a Gaussian curve of grey-scale values. In these histograms, it is not possible to trace a deep and sharp valley between two peaks representing objects and background, so that the threshold can be chosen at the bottom of this valley. Thus, from the visual inspection of this histogram no single thresholding value can be inferred to segment the region of interest in the image.

\section{Image post-processing}

In Figure 2, we demonstrate the visual result of applying the different thresholding strategies (in the left square the result of applying each of the global strategies, and in the right square the result of applying each of the local strategies). The original image of the CC is in the center for comparison. Figure 2 illustrates the pronounced differences of applying local and global thresholding strategies, that are evidenced by the different black and white regions highlighted by each thresholding strategy. All the global thresholding strategies produced binary images that qualitatively appeared identical. The local methods generated a more homogeneous appearance.

\section{Quantification parameters}

Figure 3 illustrates the differences in the quantification of the four considered CC FD metrics (either the FD number- $\mathrm{A}$, total FD area-B, mean FD size- $\mathrm{C}$, and FD density-D) using the six considered thresholding strategies applied to a single typical OCTA scan. As seen in the graphs, we verified a high amount of variation for each of the quantitative parameters according to the used method. The quantitative parameters generated after applying global strategies achieved a less dispersive distribution, that is in accordance with the observation in Figure 2. By contrast, measurements resulting from applying local strategies generated more dispersed values, as seen in the boxplots.

\section{Reproducibility of CC FD quantification}

The repeatability of CC FD quantification after applying each thresholding strategy was evaluated for each individual CC quantitative parameter (FD number, mean FD size, total FD area and FD density) using the four OCTA consecutive scans (Table 1). Globally, the ICC was superior in the quantification of FD number (ranging between 0.852 to 0.964 ) followed by FD density (ranging from 0.786 to 0.974). No isolated strategy was found to be significantly superior than the others in analyzing repeated scans, as demonstrated by the overlapping of the ICC $95 \%$ CI presented in Table 1.

We compared the repeatability of global versus local thresholding strategies for evaluating each of the four considered CC quantitative parameters (FD number, mean FD size, total FD area and FD density). As seen in Table 2, the agreement was significantly superior for local versus global strategies for all the four quantitative parameters. Local strategies achieved an ICC of 0.978 (95\% CI: 0.967$0.986)$ for FD number quantification, 0.950 (95\% CI: 0.926-0.969) for FD area, 0.925 (95\% CI: 0.889-0.952) for average FD size and 0.958 (95\% CI: 0.936-0.974) for FD 
GLOBAL

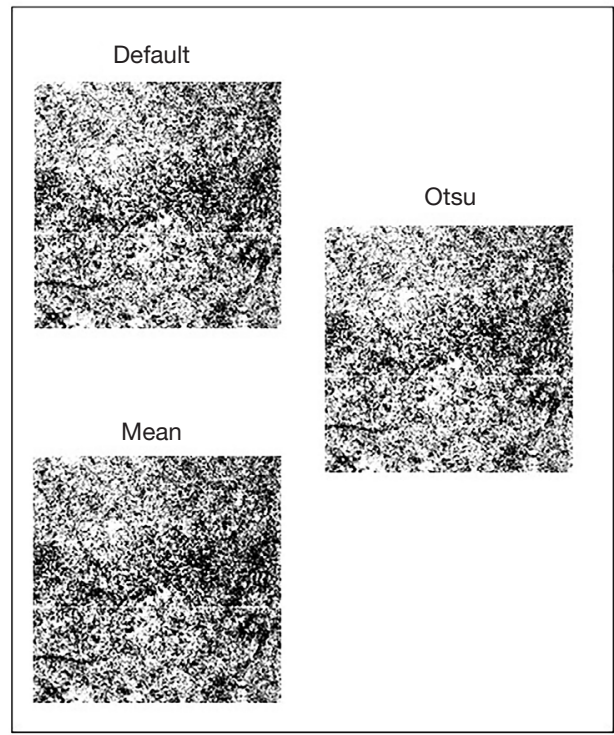

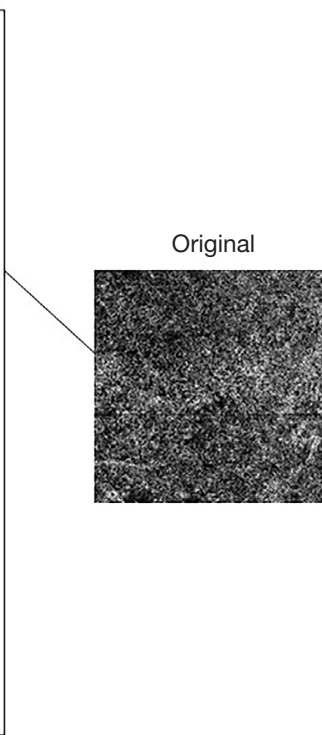

LOCAL

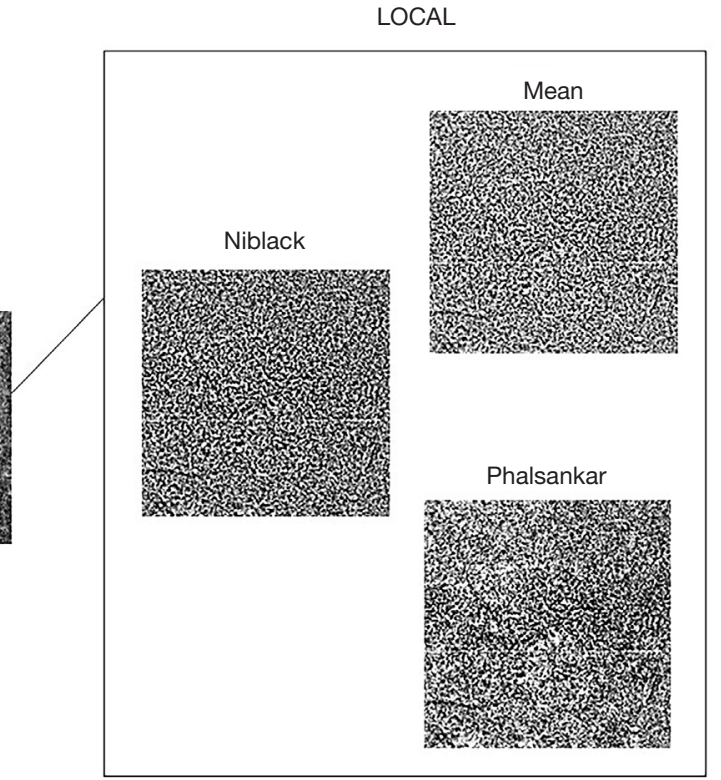

Figure 2 The figure illustrates one of the CC images in its 8-bit original form and the results after applying the 6 different thresholding strategies. Analysis was performed using Image J V. 1.51 (National Institutes of Health, Bethesda). CC, choriocapillaris.

A

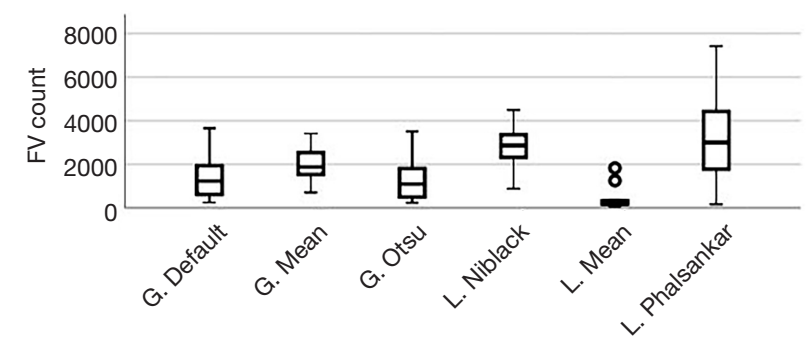

C

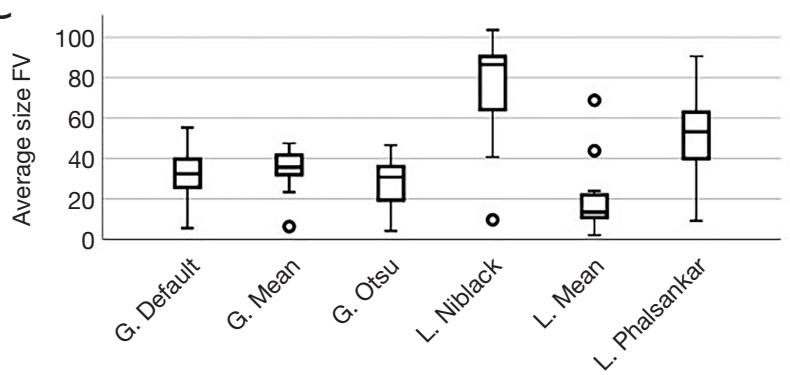

B

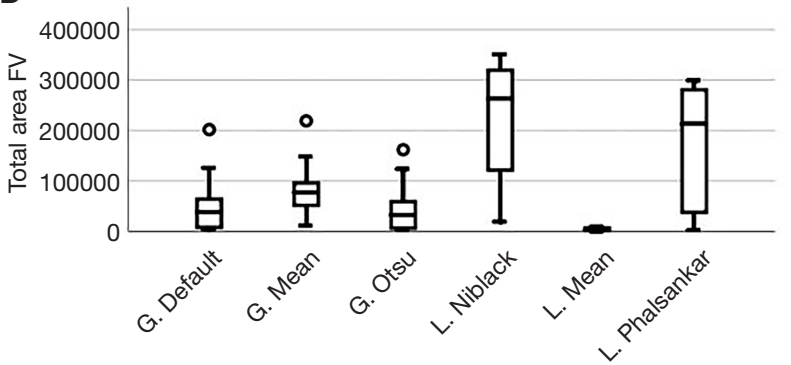

D

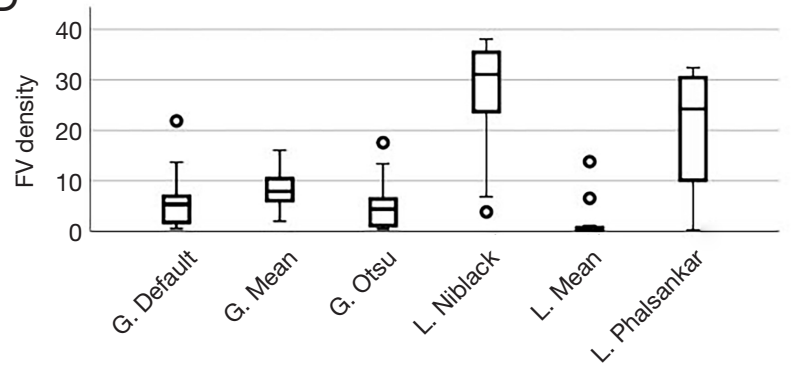

Figure 3 Differences in the quantification of the four considered CC metrics (either the FD number-A, total FD area-B, mean FD sizeC, and FD density-D) using the six considered thresholding strategies (local mean, local Phansalkar, local Niblack, global mean, global Otsu, global default) in the same scan. Individual boxplots show the median with the 25 th-75th percentile (box) and range (brackets). CC, choriocapillaris; FD, flow deficits; L., local; G., global. 
Table 1 Agreement among the four scans for each parameter measured using each of the six thresholding strategies

\begin{tabular}{|c|c|c|}
\hline $\begin{array}{l}\text { Quantitative } \\
\text { parameter }\end{array}$ & $\begin{array}{c}\text { Thresholding } \\
\text { strategy }\end{array}$ & ICC (95\% Cl) \\
\hline \multirow[t]{6}{*}{ N. FD } & G. Otsu & $0.909(0.820-0.960)$ \\
\hline & G. Mean & $0.852(0.730-0.983)$ \\
\hline & G. Default & $0.904(0.818-0.958)$ \\
\hline & L. Mean & $0.925(0.856-0.968)$ \\
\hline & L. Phansalkar & $0.964(0.928-0.985)$ \\
\hline & L. Niblack & $0.955(0.910-0.981)$ \\
\hline \multirow[t]{6}{*}{ FD area } & G. Otsu & $0.880(0.777-0.947)$ \\
\hline & G. Mean & $0.115(-0.064-0.395)$ \\
\hline & G. Default & $0.838(0.707-0.927)$ \\
\hline & L. Mean & $0.880(0.777-0.947)$ \\
\hline & L. Phansalkar & $0.937(0.877-0-973)$ \\
\hline & L. Niblack & $0.881(0.777-0.948)$ \\
\hline \multirow[t]{6}{*}{ FD average size } & G. Otsu & $0.771(0.605-0.894)$ \\
\hline & G. Mean & $0.627(0.412-0.813)$ \\
\hline & G. Default & $0.684(0.484-0.847)$ \\
\hline & L. Mean & $0.825(0.687-0.921)$ \\
\hline & L. Phansalkar & $0.850(0.727-0.933)$ \\
\hline & L. Niblack & $0.843(0.716-0.930)$ \\
\hline \multirow[t]{6}{*}{ FD density } & G. Otsu & $0.873(0.763-0.944)$ \\
\hline & G. Mean & $0.786(0.618-0.902)$ \\
\hline & G. Default & $0.833(0.699-0.925)$ \\
\hline & L. Mean & $0.879(0.774-0.946)$ \\
\hline & L. Phansalkar & $0.917(0.840-0.964)$ \\
\hline & L. Niblack & $0.974(0.946-0.989)$ \\
\hline
\end{tabular}

Values presented correspond to ICC. ICC, intraclass correlation coefficient; G., global; L., local; N., number; Cl, confidence interval; FD, flow deficits.

density.

Agreement among the strategies for CC quantification We verified variable degrees of correlation among the different thresholding strategies for measuring the same quantitative parameter (either the FD number, mean FD size, total FD area and FD density). All the correlation coefficients, $\mathrm{r}$, and respective $\mathrm{P}$ value are in Table 3.

Although some degree of correlation may be found
Table 2 Agreement among the four scans for each parameter measured using either local or global thresholding strategies

\begin{tabular}{lcc}
\hline $\begin{array}{l}\text { Quantitative } \\
\text { parameter }\end{array}$ & $\begin{array}{c}\text { Thresholding } \\
\text { strategy }\end{array}$ & ICC $(95 \% \mathrm{Cl})$ \\
\hline N. FD & Local & $0.978(0.967-0.986)$ \\
& Global & $0.901(0.854-0.936)$ \\
Area FD & Local & $0.950(0.926-0.969)$ \\
& Global & $0.446(0.309-0.589)$ \\
Average size FD & Local & $0.925(0.889-0.952)$ \\
& Global & $0.701(0.591-0.796)$ \\
FD density & Local & $0.958(0.936-0.974)$ \\
& Global & $0.843(0.770-0.899)$ \\
\hline
\end{tabular}

Values presented correspond to ICC. ICC, intraclass correlation coefficient; FD, flow deficits; N., number; $\mathrm{Cl}$, confidence interval.

among the measurements, the absolute agreement among the six thresholding methods for measuring the same quantitative parameter in the CC images was low, with an ICC ranging from 0.000 to $0.339-$ Table 4 . The lowest absolute agreement was found for average FD size, followed by FD area, FD density and FD number.

\section{Discussion}

In this study we systematically reviewed the thresholding strategies that have been recently used to quantify CC and evaluated their interchangeability and reproducibility. From our systematic review, we concluded that there is an unmet need for the homogenization of the methods that are used to threshold CC images. We found a marked variability in the thresholding methods that have been applied to CC angiograms, thus conditioning future aggregation of the results.

A significant number of authors choose to use customized or device-included algorithms. Although they may improve the quantification process, they have a narrow spectrum of application as they are not universally applicable due either to device conditioning or expertise programing needs. In our observational study, we evaluated three global and three local thresholding methods. We found that local thresholding methods have a superior performance in CC angiograms (either by a superior repeatability and an adequacy to CC histogram properties) and should be preferred to global ones. We also concluded that the CC metrics that are obtained through them are not 
Table 3 Correlation among the different parameters measured using six thresholding strategies

\begin{tabular}{|c|c|c|c|c|c|}
\hline Thresholding strategy 1 & Thresholding strategy 2 & FD number & Area FD & Average size FD & FD density \\
\hline \multirow{3}{*}{ G. Otsu } & G. Default & $r=0.999 ; P<0.001^{*}$ & $r=0.992 ; P<0.001^{*}$ & $r=0.969 ; P<0.001^{*}$ & $r=0.992 ; P<0.001^{*}$ \\
\hline & L. Mean & $r=0.823 ; P<0.001^{*}$ & $r=0.741 ; P<0.001^{*}$ & $r=0.687 ; P=0.002^{*}$ & $r=0.735 ; P<0.001^{*}$ \\
\hline & L. Phansalkar & $r=0.956 ; P<0.001^{*}$ & $r=0.837 ; P<0.001^{*}$ & $r=0.681 ; P=0.003^{*}$ & $r=0.859 ; P<0.001^{*}$ \\
\hline \multirow[t]{4}{*}{ G. Mean } & G. Otsu & $r=0.951 ; P<0.001^{*}$ & $r=0.892 ; P<0.001^{*}$ & $r=0.578 ; P=0.015^{\star}$ & $r=0.920 ; P<0.001^{*}$ \\
\hline & G. Default & $r=0.957 ; P<0.001^{*}$ & $r=0.875 ; P<0.001^{*}$ & $r=0.547 ; P=0.023^{*}$ & $r=0.890 ; P<0.001^{*}$ \\
\hline & L. Mean & $r=0.680 ; P<0.001^{*}$ & $r=0.556 ; P=0.017^{*}$ & $r=0.365 ; P=0.150$ & $r=0.545 ; P=0.016^{\star}$ \\
\hline & L. Phansalkar & $r=0.935 ; P<0.001^{*}$ & $r=0.876 ; P<0.001^{*}$ & $r=0.502 ; P=0.040^{*}$ & $r=0.771 ; P<0.001^{*}$ \\
\hline \multirow{4}{*}{ G. Default } & G. Mean & $r=0.957 ; P<0.001^{*}$ & $r=0.875 ; P<0.001^{*}$ & $r=0.547 ; P=0.023^{*}$ & $r=0.890 ; P<0.001^{*}$ \\
\hline & L. Mean & $r=0.813 ; P<0.001^{*}$ & $r=0.782 ; P<0.001^{*}$ & $r=0.717 ; P=0.001^{*}$ & $r=0.779 ; P<0.001^{*}$ \\
\hline & L. Phansalkar & $r=0.958 ; P<0.001^{*}$ & $r=0.802 ; P<0.001^{*}$ & $r=0.630 ; P=0.007^{*}$ & $r=0.851 ; P<0.001^{*}$ \\
\hline & L. Niblack & $r=0.468 ; P=0.050$ & $r=0.671 ; P=0.002^{*}$ & $r=-0.069 ; P=0.791$ & $r=0.795 ; P<0.001^{*}$ \\
\hline \multirow[t]{4}{*}{ L. Mean } & G. Otsu & $r=0.823 ; P<0.001^{*}$ & $r=0.741 ; P<0.001^{*}$ & $r=0.687 ; P=0.002^{*}$ & $r=0.735 ; P<0.001^{*}$ \\
\hline & G. Mean & $r=0.680 ; P<0.001^{*}$ & $r=0.556 ; P=0.017^{*}$ & $r=0.365 ; P=0.150$ & $r=0.545 ; P=0.016^{*}$ \\
\hline & G. Default & $r=0.813 ; P<0.001^{*}$ & $r=0.782 ; P<0.001^{*}$ & $r=0.717 ; P=0.001^{*}$ & $r=0.779 ; P<0.001^{*}$ \\
\hline & L. Phansalkar & $r=0.789 ; P<0.001^{*}$ & $r=0.365 ; P=0.136$ & $r=0.191 ; P=0.463$ & $r=0.841 ; P=0.037^{*}$ \\
\hline L. Phansalkar & L. Niblack & $r=0.474 ; P=0.047^{\star}$ & $r=0.628 ; P=0.005^{\star}$ & $r=-0.012 ; P=0.963$ & $r=0.863 ; P<0.001^{*}$ \\
\hline \multirow[t]{5}{*}{ L. Niblack } & G. Otsu & $r=0.467 ; P=0.051$ & $r=0.686 ; P=0.002^{*}$ & $r=-0.062 ; P=0.814$ & $r=0.826 ; P<0.001^{*}$ \\
\hline & G. Mean & $r=0.427 ; P=0.077$ & $r=0.695 ; P=0.001^{*}$ & $r=-0.286 ; P=0.266$ & $r=0.814 ; P<0.001^{*}$ \\
\hline & G. Default & $r=0.468 ; P=0.050$ & $r=0.671 ; P=0.002^{*}$ & $r=-0.069 ; P=0.791$ & $r=0.795 ; P<0.001^{*}$ \\
\hline & L. Mean & $r=0.495 ; P=0.037$ & $r=0.409 ; P=0.092$ & $r=-0.020 ; P=0.938$ & $r=0.453 ; P=0.051$ \\
\hline & L. Phansalkar & $r=0.474 ; P=0.047^{*}$ & $r=0.628 ; P=0.005^{*}$ & $r=-0.012 ; P=0.963$ & $r=0.863 ; P<0.001^{*}$ \\
\hline
\end{tabular}

Values of Pearson correlation coefficient (r) and P value are presented. * $P<0.05$. FD, flow deficits; G., global; L., local; N., number.

interchangeable. Thus, direct comparisons cannot be made from studies that adopt different thresholding strategies.

OCTA quantification was a change in the paradigm for the evaluation of most macular diseases. However, there is currently a need to improve and uniformize the segmentation methods for OCTA quantification. In addition, before any clinical trial, it is essential to precisely know the strengths and limitations of the image segmentation strategies that are being applied. As previously mentioned, the $\mathrm{CC}$ images are challenging as 
Table 4 Absolute agreement among the six thresholding strategies for measuring the same quantitative parameter in the same scan

\begin{tabular}{lc}
\hline Quantitative parameter & ICC $(95 \% \mathrm{Cl})$ \\
\hline FD number & $0.339(0.124-0.601)$ \\
Area FD & $0.224(0.063-0.468)$ \\
Average size FD & $0.000(-0.090-0.191)$ \\
FD density & $0.278(0.091-0.530)$ \\
\hline
\end{tabular}

Mean value of the four acquisitions was considered in each pair. Values presented correspond to ICC. ICC, intraclass correlation coefficient; $\mathrm{Cl}$, confidence interval; FD, flow deficits.

the intracapillary distance of the vessels is general under the resolution of OCTA devices, what does not occur in retinal capillary plexus. Thus, the CC images quantification is more prone to be influenced by the image processing methods and all sources of variability must be explored to prevent biased conclusions.

Thresholding is known to be a critical step in image segmentation as it will influence all the analysis that are subsequently applied to CC angiograms. When thresholding CC OCTA images, a balance must be struck between excluding noise and including valid signal. If the threshold is set low, then there will be more noise above the threshold (and hence in the resulting thresholded OCTA image), but the subsequent OCTA output will be less likely to have eliminated any true vasculature.

In the current study, we explored the influence of applying different thresholding strategies in the quantification of the CC FD. We found that, considering each of the thresholding strategy individually, the four CC quantitative parameters were highly correlated. This is in accordance with the study performed by Shi et al. (26), that also found excellent correlations among the percentage of CC FD and the average area of FD. However, we found that the absolute agreement among the evaluated thresholding strategies for measuring the same quantitative parameter in the CC images was low, with ICC ranging from 0.000 to 0.339. Therefore, although somewhat correlated, the CC FD values obtained using different thresholding strategies are not interchangeable and direct comparisons should not be performed among studies that use different strategies.

In this study we also demonstrated that the histogram of the CC en-face 8-bit image follow a Gaussian distribution of grey-scale values. This is in accordance to what has been described in the literature $(6,31)$ and, from this, we can conclude that global thresholding strategies will not have an adequate performance as the distribution does not suggest a value to separate the background from the foreground. By using a global thresholding strategy, we will erroneously classify noise as FD or the opposite. This was corroborated by our findings as the global thresholding strategies, as a group, achieved a significant lower reliability in the quantification of CC consecutive scans when comparing to the local ones. This was verified irrespective of FD characteristics. Therefore, local strategies should be preferred to global ones for CC FD quantitative analysis purpose. Among local strategies, we found similar repeatability and no standard could be inferred from this analysis.

To our knowledge, few studies have investigated the variability in CC quantification induced by the thresholding process. Yun et al. (32) compared the Phansalkar and a device-specific global thresholding method in images from four OCTA devices. Mehta et al. (33) also investigated CC quantitative measurements variability using four different thresholding strategies (global default, global mean, global Otsu, local mean, and local Phansalkar) in a SS OCTA. Although the previous authors concluded about the differences that exist in FD quantification when each strategy is applied in a single examination, no repeatability analysis is reported in the study and no comparison is reported among the local and global strategies as major groups. Chu et al. (20) also used SS OCTA and compared the correlation and agreement between one local thresholding method (fuzzy C-means algorithm) and one global thresholding method (an algorithm that uses standard deviation from a young normal database) and concluded about the strong correlation between the two methods for measuring FD density and mean FD size. In the another study (23), Chu et al. compared the variation in quantitative CC metrics after applying both fuzzy C-means thresholding method and Phansalkar method (using different pixel radius) and found heterogeneous results. Interestingly the authors also performed a repeatability study and ICC values reported for CC metrics using Phansalkar method are superior than those we found. This may be explained either by the different post-processing of the signal, either by the use SS OCTA device to perform acquisitions. In SS OCTA, the longer wavelength that has better penetration through the RPE and less sensitivity roll-off into the choroid, which results in an improvement in the likelihood of detecting the weaker signals from under the retinal pigment epithelium (34). Previous reports have reported the superiority of SSOCTA for detecting macular neovascularization under the 
retinal pigmented epithelium $(35,36)$. Thus, we may infer that SS technology will have a superior reliability for the quantification of CC FD than SD do.

Our study has several limitations. Firstly, as previously mentioned by Chu et al. (23), there is a lack of ground truth for $\mathrm{CC}$ vasculature, as all the techniques to validate it are invasive involving sacrificing animals to compare harvested eyes with previous imaging. Secondly, we are aware that the quantitative CC parameters may be significantly influenced by small differences in the slab selection (21). We did not stratify the results by slab classification as that was not the purpose of the review. In our observational study, we opted to maintain the manufacturer CC segmentation for clinical relevance. We are also aware of other sources of variability in OCTA images quantification as the use of different algorithms and averaging $(13,37)$. Thus, more studies in the field are needed. Finally, our study only included healthy eyes from young patients. It is thus unpredictable how much our results would change if the validation was performed in patients with significant retinal diseases. Further studies are needed to evaluate the behavior of these thresholding methods in more complex and noisy scans as in the presence of macular neovascularization and to evaluate their discriminative power to differentiate normal versus abnormal CC.

Besides all the potential limitations, our study has several strengths. We report the heterogeneity of thresholding process in CC quantification thus raising awareness for the need of uniformization to achieve comparable conclusions. We also evaluated the interchangeability among different algorithms for measuring the same parameter and the reproducibility of each algorithm for measuring repeated scans. This gives a broad perspective of the variability that is inherent to choosing different thresholding strategies. In addition, no data exists for SD device regarding this topic. We believe our research will help future researchers in the field to improve their thresholding selection.

\section{Conclusions}

As OCTA becomes incorporated into clinical decision making, the ability to understand the thresholding process, and the artifacts that this process introduces in CC FD quantification, is of utmost importance. We found no interchangeability among different thresholding strategies for quantifying CC FD. Thus, direct comparisons should not be considered in future studies. Local thresholding strategies demonstrated a superior repeatability and should be preferred to the global ones for CC quantitative analysis in OCTA angiograms. There is currently an unmet need for a uniform strategy to quantify CC in future studies.

\section{Acknowledgments}

Funding: None.

\section{Footnote}

Conflicts of Interest: All authors have completed the ICMJE uniform disclosure form (available at http://dx.doi. org/10.21037/qims-20-340). The authors have no conflicts of interest to declare.

Ethical Statement: The study was approved by the Institutional Ethics Committee of Centro Hospitalar de Entre o Douro e Vouga (No. CA-0708/18-0t_MP/AC) and adhered to the tenets of the Declaration of Helsinki and its later amendments. Informed consent was obtained from participants before the inclusion in the study.

Open Access Statement: This is an Open Access article distributed in accordance with the Creative Commons Attribution-NonCommercial-NoDerivs 4.0 International License (CC BY-NC-ND 4.0), which permits the noncommercial replication and distribution of the article with the strict proviso that no changes or edits are made and the original work is properly cited (including links to both the formal publication through the relevant DOI and the license). See: https://creativecommons.org/licenses/by-nc-nd/4.0/.

\section{References}

1. Nickla DL, Wallman J. The multifunctional choroid. Prog Retin Eye Res 2010;29:144-68.

2. Spraul CW, Lang GE, Grossniklaus HE, Lang GK. Histologic and morphometric analysis of the choroid, Bruch's membrane, and retinal pigment epithelium in postmortem eyes with age-related macular degeneration and histologic examination of surgically excised choroidal neovascular membranes. Surv Ophthalmol 1999;44 Suppl 1:S10-32.

3. McLeod DS, Lutty GA. High-resolution histologic analysis of the human choroidal vasculature. Invest Ophthalmol Vis Sci 1994;35:3799-811.

4. Biesemeier A, Taubitz T, Julien S, Yoeruek E, Schraermeyer U. Choriocapillaris breakdown precedes 
retinal degeneration in age-related macular degeneration. Neurobiol Aging 2014;35:2562-73.

5. Cohen SM, Shen JH, Smiddy WE. Laser energy and dye fluorescence transmission through blood in vitro. Am J Ophthalmol 1995;119:452-7.

6. Zhang Q, Zheng F, Motulsky EH, Gregori G, Chu Z, Chen CL, Li C, de Sisternes L, Durbin M, Rosenfeld PJ, Wang RK. A novel strategy for quantifying choriocapillaris flow voids using swept-source OCT angiography. Invest Ophthalmol Vis Sci 2018;59:203-11.

7. Kashani AH, Chen CL, Gahm JK, Zheng F, Richter GM, Rosenfeld PJ, Shi Y, Wang RK. Optical coherence tomography angiography: a comprehensive review of current methods and clinical applications. Prog Retin Eye Res 2017;60:66-100.

8. Chan G, Balaratnasingam C, Xu J, Mammo Z, Han S, Mackenzie P, Merkur A, Kirker A, Albiani D, Sarunic MV, Yu DY. In vivo optical imaging of human retinal capillary networks using speckle variance optical coherence tomography with quantitative clinico-histological correlation. Microvasc Res 2015;100:32-9.

9. Chen CL, Wang RK. Optical coherence tomography based angiography [Invited]. Biomed Opt Express 2017;8:1056-82.

10. Lupidi M, Coscas F, Cagini C, Fiore T, Spaccini E, Fruttini D, Coscas G. Automated quantitative analysis of retinal microvasculature in normal eyes on optical coherence tomography angiography. Am J Ophthalmol 2016;169:9-23.

11. Chu Z, Lin J, Gao C, Xin C, Zhang Q, Chen CL, Roisman L, Gregori G, Rosenfeld PJ, Wang RK. Quantitative assessment of the retinal microvasculature using optical coherence tomography angiography. J Biomed Opt 2016;21:66008.

12. Sambhav K, Grover S, Chalam KV. The application of optical coherence tomography angiography in retinal diseases. Surv Ophthalmol 2017;62:838-66.

13. Cole ED, Moult EM, Dang S, Choi W, Ploner SB, Lee B, Louzada R, Novais E, Schottenhamml J, Husvogt L, Maier A, Fujimoto JG, Waheed NK, Duker JS. The definition, rationale, and effects of thresholding in OCT angiography. Ophthalmol Retina 2017;1:435-47.

14. Rasband WS. ImageJ, U. S. National Institutes of Health, Bethesda, Maryland, USA. 1997-2018. Available online: https://imagej.nih.gov/ij/

15. Olver JM. Functional anatomy of the choroidal circulation: methyl methacrylate casting of human choroid. Eye 1990;4:262-72.
16. Torczynski E, Tso MOM. The architecture of the choriocapillaris at the posterior pole. Am J Ophthalmol 1976;81:428-40.

17. Fryczkowski AW. Anatomical and functional choroidal lobuli. Int Ophthalmol 1994;18:131-41.

18. Nassisi M, Tepelus T, Nittala MG, Sadda SR. Choriocapillaris flow impairment predicts the development and enlargement of drusen. Graefes Arch Clin Exp Ophthalmol 2019;257:2079-85.

19. Zhang Q, Shi Y, Zhou H, Gregori G, Chu Z, Zheng F, Motulsky EH, de Sisternes L, Durbin M, Rosenfeld PJ, Wang RK. Accurate estimation of choriocapillaris flow deficits beyond normal intercapillary spacing with swept source OCT angiography. Quant Imaging Med Surg 2018;8:658-66.

20. Chu Z, Zhang Q, Zhou H, Shi Y, Zheng F, Gregori G, Rosenfeld PJ, Wang RK. Quantifying choriocapillaris flow deficits using global and localized thresholding methods: a correlation study. Quant Imaging Med Surg 2018;8:1102-12.

21. Byon I, Nassisi M, Borrelli E, Sadda SR. Impact of slab selection on quantification of choriocapillaris flow deficits by optical coherence tomography angiography. Am J Ophthalmol 2019;208:397-405.

22. Alagorie AR, Verma A, Nassisi M, Sadda SR. Quantitative assessment of choriocapillaris flow deficits in eyes with advanced age-related macular degeneration versus healthy eyes. Am J Ophthalmol 2019;205:132-9.

23. Chu Z, Gregori G, Rosenfeld PJ, Wang RK.

Quantification of choriocapillaris with optical coherence tomography angiography: a comparison study. Am J Ophthalmol 2019;208:111-23.

24. Chu Z, Zhou H, Cheng Y, Zhang Q, Wang RK. Improving visualization and quantitative assessment of choriocapillaris with swept source OCTA through registration and averaging applicable to clinical systems. Sci Rep 2018;8:16826.

25. Zheng F, Zhang Q, Shi Y, Russell JF, Motulsky EH, Banta JT, Chu Z, Zhou H, Patel NA, de Sisternes L, Durbin MK, Feuer W, Gregori G, Wang R, Rosenfeld PJ. Agedependent changes in the macular choriocapillaris of normal eyes imaged with swept-source optical coherence tomography angiography. Am J Ophthalmol 2019;200:110-22.

26. Shi Y, Zhang Q, Zheng F, Russell JF, Motulsky EH, Banta JT, Chu Z, Zhou H, Patel NA, de Sisternes L, Durbin MK, Feuer W, Gregori G, Wang RK, Rosenfeld PJ. Correlations between different choriocapillaris flow 
deficit parameters in normal eyes using swept source OCT angiography. Am J Ophthalmol 2020;209:18-26.

27. Glasbey CA. An analysis of histogram-based thresholding algorithms. CVGIP Graph Model Image Process 1993;55:532-7.

28. Sezgin M, Sankur B. Survey over image thresholding techniques and quantitative performance evaluation. J Electron Imaging 2004;13:146-8.

29. Carabias DM. Analysis of image thresholding methods for their application to augmented reality environments. 2012. Available online: https://pdfs.semanticscholar.org/0c61/96 480396c12a203ca16f0b51e34b260f3eb3.pdf

30. Lee SU, Yoon Chung S, Park RH. A comparative performance study of several global thresholding techniques for segmentation. Comput Vision, Graph Image Process 1990;52:171-90.

31. Spaide RF. Ising model of choriocapillaris flow. Retina 2018;38:79-83.

32. Yun C, Nam KT, Park S, Hwang SY, Oh J. Features of the choriocapillaris on four different optical coherence tomography angiography devices. Int Ophthalmol 2020;40:325-33.

33. Mehta N, Liu K, Alibhai AY, Gendelman I, Braun PX, Ishibazawa A, Sorour O, Duker JS, Waheed NK. Impact of binarization thresholding and brightness/contrast adjustment methodology on optical coherence tomography angiography image quantification. Am J Ophthalmol 2019;205:54-65.

34. Potsaid B, Gorczynska I, Srinivasan VJ, Chen Y, Jiang J, Cable A, Fujimoto JG. Ultrahigh speed spectral/Fourier domain OCT ophthalmic imaging at 70,000 to 312,500 axial scans per second. Opt Express 2008;16:15149-69.

35. Miller AR, Roisman L, Zhang Q, Zheng F, Rafael de Oliveira Dias JR, Yehoshua Z, Schaal KB, Feuer W, Gregori G, Chu Z, Chen CL, Kubach S, An L, Stetson PF, Durbin MK, Wang RK, Rosenfeld PJ. Comparison between spectral-domain and swept-source optical coherence tomography angiographic imaging of choroidal neovascularization. Invest Ophthalmol Vis Sci 2017;58:1499-505.

36. Novais EA, Mehreen Adhi, Moult EM, Louzada RN, Cole ED, Husvogt L, Lee B, Dang S, Regatieri CVS, Witkin AJ, Baumal CR, Hornegger J, Jayaraman V, Fujimoto JG, Duker JS, Waheed NK. Choroidal neovascularization analyzed on ultra-high speed swept source optical coherence tomography angiography compared to spectral domain optical coherence tomography angiography. Am J Ophthalmol 2016;164:80-8.

37. Zhou K, Song S, Zhang Q, Chu Z, Huang Z, Wang RK. Visualizing choriocapillaris using swept-source optical coherence tomography angiography with various probe beam sizes. Biomed Opt Express 2019;10:2847-60.
Cite this article as: Laiginhas $\mathrm{R}$, Cabral D, Falcão $M$. Evaluation of the different thresholding strategies for quantifying choriocapillaris using optical coherence tomography angiography. Quant Imaging Med Surg 2020;10(10):1994-2005. doi: 10.21037/qims-20-340 


\section{Supplementary}

\section{Supplementary file 1 Thresholding strategies-definitions}

\section{Global thresholding}

The mean global threshold method (27) takes the average grayscale value across the image as a threshold value. The default global method which is a variation of the IsoData algorithm that divides the image into foreground and background pixels and iteratively tries different threshold values until finding one larger than the mean value (38). The Otsu global algorithm determines a threshold value that minimizes the variance in grayscale values within each class and maximizes variance between the classes (39).

\section{Local thresholding}

Local mean method selects the threshold as the mean of the local grayscale distribution (14). In local thresholding methods, the threshold for binarization is computed for each pixel according to the image characteristics within a window of radius $r$. The default $\mathrm{r}$ value in Image $\mathrm{J}$ is 15 pixels. This valued was not changed as we conclude that the most of the authors from previous CC quantitative studies left this value unchanged, according to what was originally reported by Spaide (40). Niblack's thresholding method is the oldest local binarization method found in the literature. In this method, the estimation of a threshold value is based on the calculation of local mean and standard deviation of pixels value in a local window confined to an image (41). The Phansalkar algorithm incorporates the mean and standard deviations of the grayscale values in the local area. It was designed for images with a variable appearance and particularly to optimize binarization thresholding in low contrast images (42).

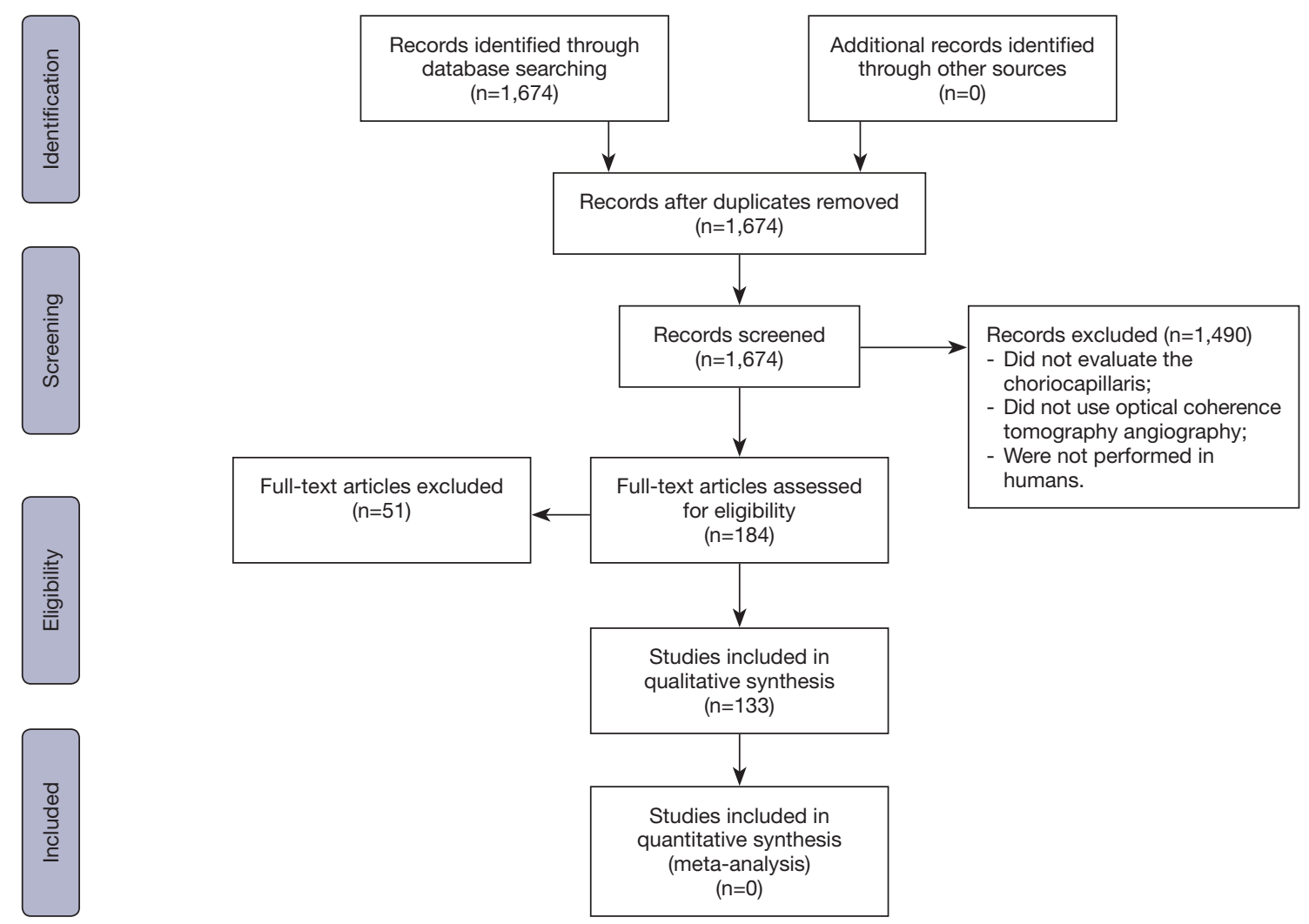

Figure S1 PRISMA 2009 flow diagram. 
Table S1 Summary of the thresholding strategies found through the systematic review

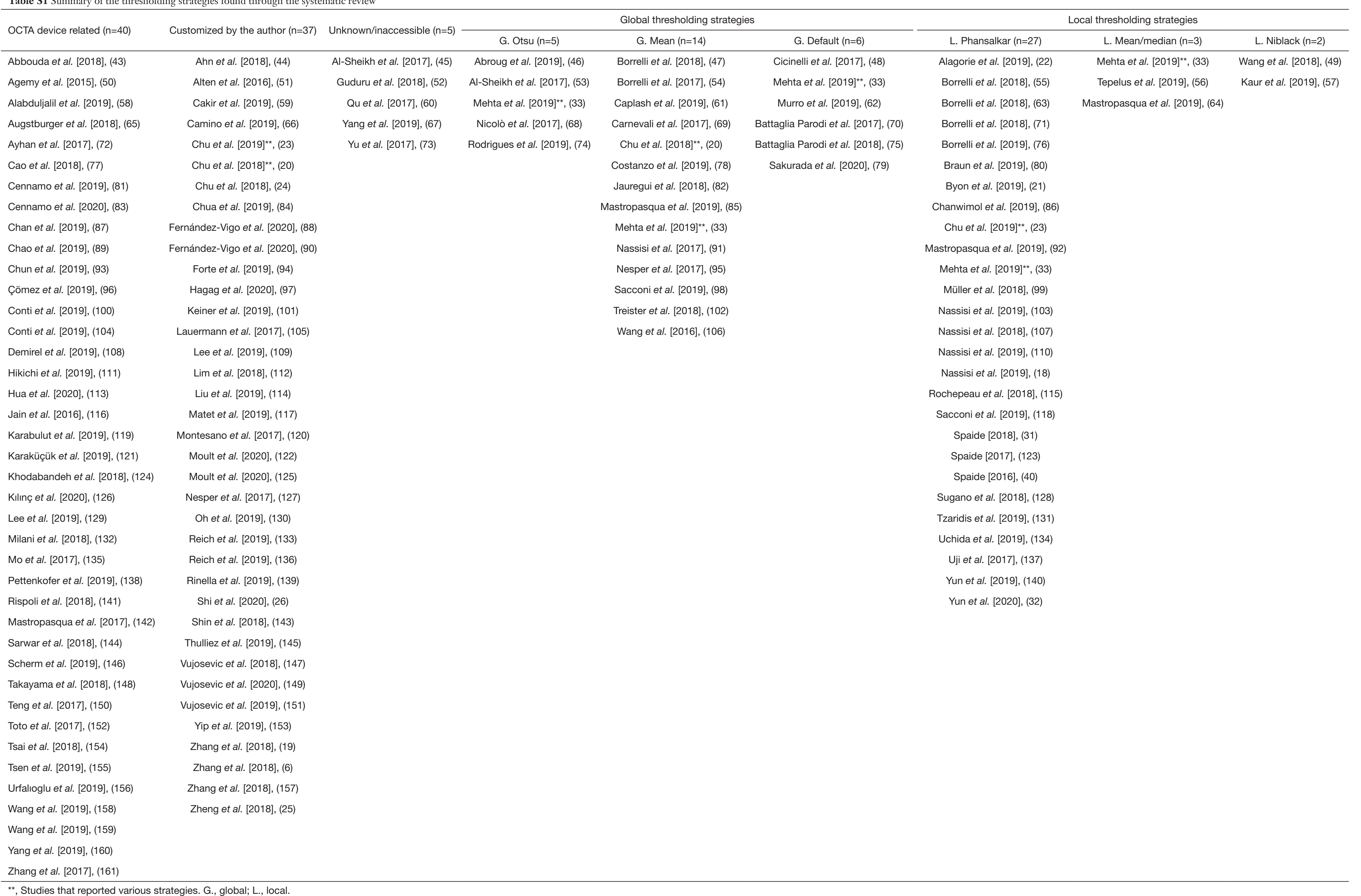




\section{References}

38. Ridler TW, Calvard S. Picture thresholding using an iterative selection method. IEEE Trans Syst Man Cybern 1978;8:630-2.

39. Otsu N. A threshold selection method from gray-level histograms. IEEE Trans Syst Man Cybern 1979;9:62-6.

40. Spaide RF. Choriocapillaris flow features follow a power law distribution: implications for characterization and mechanisms of disease progression. Am J Ophthalmol 2016;170:58-67.

41. Niblack W. An introduction to digital image processing. Englewood Cliffs: Prentice-Hall, 1986.

42. Phansalkar N, More S, Sabale A, Joshi M. Adaptive local thresholding for detection of nuclei in diversity stained cytology images. Calicut: 2011 International Conference on Communications and Signal Processing, 2011:218-20.

43. Abbouda A, Dubis AM, Webster AR, Moosajee M. Identifying characteristic features of the retinal and choroidal vasculature in choroideremia using optical coherence tomography angiography. Eye 2018;32:563-71.

44. Ahn J, Yoo G, Kim JT, Kim SW, Oh J. Choriocapillaris layer imaging with swept-source optical coherence tomography angiography in lamellar and full-thickness macular hole. Graefes Arch Clin Exp Ophthalmol 2018;256:11-21.

45. Al-Sheikh M, Falavarjani KG, Pfau M, Uji A, Le PP, Sadda SR. Quantitative features of the choriocapillaris in healthy individuals using swept-source optical coherence tomography angiography. Ophthalmic Surg Lasers Imaging Retina 2017;48:623-31.

46. Abroug N, Ksiaa I, Lupidi M, Nabi W, Attia S, Jelliti B, Khochtali S, Khairallah M. Swept source-OCT and swept source-OCT angiography findings in posterior microphthalmos. Int Ophthalmol 2019;39:2709-19.

47. Borrelli E, Mastropasqua R, Senatore A, Palmieri M, Toto L, Sadda SR, Mastropasqua L. Impact of choriocapillaris flow on multifocal electroretinography in intermediate age-related macular degeneration eyes. Invest Ophthalmol Vis Sci 2018;59:AMD25-30.

48. Cicinelli MV, Rabiolo A, Marchese A, de Vitis L, Carnevali A, Querques L, Bandello F, Querques G. Choroid morphometric analysis in non-neovascular age-related macular degeneration by means of optical coherence tomography angiography. Br J Ophthalmol 2017;101:1193-200.

49. Wang JC, Laíns I, Silverman RF, Sobrin L, Vavvas DG, Miller JW, Miller JB. Visualization of choriocapillaris and choroidal vasculature in healthy eyes with en face sweptsource optical coherence tomography versus angiography. Transl Vis Sci Technol 2018;7:25.

50. Agemy SA, Scripsema NK, Shah CM, Chui T, Garcia PM, Lee JG, Gentile RC, Hsiao YS, Zhou Q, Ko T, Rosen RB. Retinal vascular perfusion density mapping using optical coherence tomography angiography in normals and diabetic retinopathy patients. Retina 2015;35:2353-63.

51. Alten F, Heiduschka P, Clemens CR, Eter N. Exploring choriocapillaris under reticular pseudodrusen using OCT-Angiography. Graefes Arch Clin Exp Ophthalmol 2016;254:2165-73.

52. Guduru A, Al-Sheikh M, Gupta A, Ali H, Jalali

S, Chhablani J. Quantitative assessment of the choriocapillaris in patients with retinitis pigmentosa and in healthy individuals using oct angiography. Ophthalmic Surg Lasers Imaging Retina 2018;49:e122-8.

53. Al-Sheikh M, Phasukkijwatana N, Dolz-Marco R, Rahimi M, Iafe NA, Freund KB, Sadda SR, Sarraf D. Quantitative OCT angiography of the retinal microvasculature and the choriocapillaris in myopic eyes. Invest Ophthalmol Vis Sci 2017;58:2063-9.

54. Borrelli E, Uji A, Sarraf D, Sadda SVR. Alterations in the choriocapillaris in intermediate age-related macular degeneration. Invest Ophthalmol Vis Sci 2017;58:4792-8.

55. Borrelli E, Lonngi M, Balasubramanian S, Tepelus TC, Baghdasaryan E, Pineles SL, Velez FG, Sarraf D, Sadda $\mathrm{SR}$, Tsui I. Increased choriocapillaris vessel density in amblyopic children: a case-control study. J AAPOS 2018;22:366-70.

56. Tepelus TC, Song S, Borrelli E, Nittala MG, Baghdasaryan E, Sadda SR, Chopra V. Quantitative analysis of retinal and choroidal vascular parameters in patients with low tension glaucoma. J Glaucoma 2019;28:557-62.

57. Kaur S, Singh SR, Katoch D, Dogra MR, Sukhija J. Optical coherence tomography angiography in amblyopia. Ophthalmic Surg Lasers Imaging Retina 2019;50:e294-9.

58. Alabduljalil T, Patel RC, Alqahtani AA, Gao SS, Gale MJ, Zhang M, Jia Y, Huang D, Chiang PW, Chen R, Wang J, Weleber RG, Pennesi ME, Yang P. Correlation of outer retinal degeneration and choriocapillaris loss in stargardt disease using en face optical coherence tomography and optical coherence tomography angiography. Am J Ophthalmol 2019;202:79-90.

59. Cakir B, Reich M, Lang S, Bühler A, Ehlken C, Grundel B, Stech M, Reichl S, Stahl A, Böhringer D, Agostini H, Lange C. OCT angiography of the choriocapillaris in central serous chorioretinopathy: a quantitative subgroup 
analysis. Ophthalmol Ther 2019;8:75-86.

60. Qu Y, Gong D, Yu W, Dong F. Characteristics of the choriocapillaris layer in optical coherence tomography angiography of acute central serous chorioretinopathy. Ophthalmic Surg Lasers Imaging Retina 2017;48:1000-5.

61. Caplash S, Kodati S, Cheng SK, Akanda M, Vitale S, Thompson I, Gangaputra S, Sen HN. Repeatability of optical coherence tomography angiography in uveitic eyes. Transl Vis Sci Technol 2019;8:17.

62. Murro V, Mucciolo DP, Giorgio D, Sodi A, Passerini I, Virgili G, Rizzo S. Optical coherence tomography angiography (OCT-A) in young choroideremia (CHM) patients. Ophthalmic Genet 2019;40:201-6.

63. Borrelli E, Shi Y, Uji A, Balasubramanian S, Nassisi M, Sarraf D, Sadda SR. Topographic analysis of the choriocapillaris in intermediate age-related macular degeneration. Am J Ophthalmol 2018;196:34-43.

64. Mastropasqua R, D'Aloisio R, Di Antonio L, Erroi E, Borrelli E, Evangelista F, D'Onofrio G, Di Nicola M, Di Martino G, Toto L. Widefield optical coherence tomography angiography in diabetic retinopathy. Acta Diabetol 2019;56:1293-303.

65. Augstburger E, Zéboulon P, Keilani C, Baudouin C, Labbé A. Retinal and choroidal microvasculature in nonarteritic anterior ischemic optic neuropathy: an optical coherence tomography angiography study. Invest Ophthalmol Vis Sci 2018;59:870-7.

66. Camino A, Guo Y, You Q, Wang J, Huang D, Bailey ST, Jia Y. Detecting and measuring areas of choriocapillaris low perfusion in intermediate, non-neovascular age-related macular degeneration. Neurophotonics 2019;6:041108.

67. Yang D, Cao D, Huang Z, Xie J, Meng Q, Dong X, Hu Y, Zeng Y, Zhang L. Macular capillary perfusion in Chinese patients with diabetic retinopathy obtained with optical coherence tomography angiography. Ophthalmic Surg Lasers Imaging Retina 2019;50:e88-95.

68. Nicolò M, Rosa R, Musetti D, Musolino M, Saccheggiani $\mathrm{M}$, Traverso CE. Choroidal vascular flow area in central serous chorioretinopathy using swept-source optical coherence tomography angiography. Invest Ophthalmol Vis Sci 2017;58:2002-10.

69. Carnevali A, Sacconi R, Corbelli E, Tomasso L, Querques L, Zerbini G, Scorcia V, Bandello F, Querques G. Optical coherence tomography angiography analysis of retinal vascular plexuses and choriocapillaris in patients with type 1 diabetes without diabetic retinopathy. Acta Diabetol 2017;54:695-702.

70. Battaglia Parodi M, Cicinelli MV, Rabiolo A, Pierro L,
Gagliardi M, Bolognesi G, Bandello F. Vessel density analysis in patients with retinitis pigmentosa by means of optical coherence tomography angiography. $\mathrm{Br} \mathrm{J}$ Ophthalmol 2017;101:428-32.

71. Borrelli E, Souied EH, Freund KB, Querques G, Miere A, Gal-Or O, Sacconi R, Sadda SR, Sarraf D. Reduced choriocapillaris flow in eyes with type 3 neovascularization and age-related macular degeneration. Retina 2018;38:1968-76.

72. Ayhan Z, Kaya M, Ozturk T, Karti O, Oner FH. Evaluation of macular perfusion in healthy smokers by using optical coherence tomography angiography. Ophthalmic Surg Lasers Imaging Retina 2017;48:617-22.

73. Yu Y, Teng Y, Gao M, Liu X, Chen J, Liu W. Quantitative choriocapillaris perfusion before and after vitrectomy in idiopathic epiretinal membrane by optical coherence tomography angiography. Ophthalmic Surg Lasers Imaging Retina 2017;48:906-15.

74. Rodrigues TM, Marques JP, Soares M, Simão S, Melo P, Martins A, Figueira J, Murta JN, Silva R. Macular OCTangiography parameters to predict the clinical stage of nonproliferative diabetic retinopathy: an exploratory analysis. Eye (Lond) 2019;33:1240-7.

75. Battaglia Parodi M, Rabiolo A, Cicinelli MV, Iacono P, Romano F, Bandello F. Quantitative analysis of optical coherence tomography angiography in adult-onset foveomacular vitelliform. Retina 2018;38:237-44.

76. Borrelli E, Uji A, Toto L, Viggiano P, Evangelista F, Mastropasqua R. In vivo mapping of the choriocapillaris in healthy eyes: a widefield swept-source OCT angiography study. Ophthalmol Retina 2019;3:979-84.

77. Cao D, Yang D, Huang Z, Zeng Y, Wang J, Hu Y, Zhang L. Optical coherence tomography angiography discerns preclinical diabetic retinopathy in eyes of patients with type 2 diabetes without clinical diabetic retinopathy. Acta Diabetol 2018;55:469-77.

78. Costanzo E, Parravano M, Gilardi M, Cavalleri M, Sacconi R, Aragona E, Varano M, Bandello F, Querques G. Microvascular retinal and choroidal changes in retinal vein occlusion analyzed by two different optical coherence tomography angiography devices. Ophthalmologica 2019;242:8-15.

79. Sakurada Y, Fragiotta S, Leong BCS, Parikh R, Hussnain SA, Freund KB. Relationship between choroidal vascular hyperpermeability, choriocapillaris flow density, and choroidal thickness in eyes with pachychoroid pigment epitheliopathy. Retina 2020;40:657-62.

80. Braun PX, Mehta N, Gendelman I, Alibhai AY, Moult 
EM, Zhao Y, Ishibazawa A, Sorour O, Konstantinou EK, Baumal CR, Witkin AJ, Fujimoto JG, Duker JS, Waheed NK. Global analysis of macular choriocapillaris perfusion in dry age-related macular degeneration using sweptsource optical coherence tomography angiography. Invest Ophthalmol Vis Sci 2019;60:4985-90.

81. Cennamo G, Cennamo M, Caputo G, Mirra F, Pafundi PC, de Crecchio G, Giovanni Cennamo G. Optical coherence tomography angiography to assess vascular remodeling of the choriocapillaris after low-fluence photodynamic therapy for chronic central serous chorioretinopathy. Photodiagnosis Photodyn Ther 2019;27:162-6.

82. Jauregui R, Park KS, Duong JK, Mahajan VB, Tsang $\mathrm{SH}$. Quantitative progression of retinitis pigmentosa by optical coherence tomography angiography. Sci Rep 2018;8:13130.

83. Cennamo G, Montorio D, D’Alessandro A, Napolitano P, D'Andrea L, Tranfa F. Prospective study of vessel density by optical coherence tomography angiography after intravitreal bevacizumab in exudative age-related macular degeneration. Ophthalmol Ther 2020;9:77-85.

84. Chua J, Chin CWL, Tan B, Wong SH, Devarajan K, Le TT, Ang M, Wong TY, Schmetterer L. Impact of systemic vascular risk factors on the choriocapillaris using optical coherence tomography angiography in patients with systemic hypertension. Sci Rep 2019;9:5819.

85. Mastropasqua R, Senatore A, Di Antonio L, Di Nicola M, Marchioni M, Perna F, Amore F, Borrelli E, De Nicola C, Carpineto P, Toto L. Correlation between choriocapillaris density and retinal sensitivity in stargardt disease. J Clin Med 2019;8:1432.

86. Chanwimol K, Balasubramanian S, Nassisi M, Gaw SL, Janzen C, Sarraf D, Sadda SR, Tsui I. Retinal vascular changes during pregnancy detected with optical coherence tomography angiography. Invest Ophthalmol Vis Sci 2019;60:2726-32.

87. Chan SY, Pan CT, Wang Q, Shi XH, Jonas JB, Wei W Bin. Optical coherent tomographic angiographic pattern of the deep choroidal layer and choriocapillaris after photodynamic therapy for central serous chorioretinopathy. Graefes Arch Clin Exp Ophthalmol 2019;257:1365-72.

88. Fernández-Vigo JI, Kudsieh B, Shi H, Arriola-Villalobos P, Donate-López J, García-Feijóo J, Ruiz-Moreno JM, Fernández-Vigo JÁ. Normative database and determinants of macular vessel density measured by optical coherence tomography angiography. Clin Exp Ophthalmol
2020;48:44-52.

89. Chao SC, Yang SJ, Chen HC, Sun CC, Liu CH, Lee CY. Early macular angiography among patients with glaucoma, ocular hypertension, and normal subjects. J Ophthalmol 2019;2019:7419470.

90. Fernández-Vigo JI, Kudsieh B, Macarro-Merino A, Arriola-Villalobos P, Martínez-de-la-Casa JM, GarcíaFeijóo J, Fernández-Vigo JÁ. Reproducibility of macular and optic nerve head vessel density measurements by swept-source optical coherence tomography angiography. Eur J Ophthalmol 2020;30:756-63.

91. Nassisi M, Lavia C, Alovisi C, Musso L, Eandi CM. Shortterm choriocapillaris changes in patients with central serous chorioretinopathy after half-dose photodynamic therapy. Int J Mol Sci 2017;18:2468.

92. Mastropasqua R, Viggiano P, Borrelli E, Evangelista F, Libertini D, Di Antonio L, Toto L. In vivo mapping of the choriocapillaris in high myopia: a widefield swept source optical coherence tomography angiography. Sci Rep 2019;9:18932.

93. Chun LY, Silas MR, Dimitroyannis RC, Ho K, Skondra D. Differences in macular capillary parameters between healthy black and white subjects with optical coherence tomography angiography (OCTA). PLoS One 2019; 14:e0223142.

94. Forte R, Haulani H, Dyrda A, Jürgens I. Swept source optical coherence tomography angiography in patients treated with hydroxychloroquine: correlation with morphological and functional tests. Br J Ophthalmol 2019. [Epub ahead of print]. doi: 10.1136/ bjophthalmol-2018-313679.

95. Nesper PL, Soetikno B'T, Fawzi AA. Choriocapillaris nonperfusion is associated with poor visual acuity in eyes with reticular pseudodrusen. Am J Ophthalmol 2017; 174:42-55.

96. Çömez A, Beyoğlu A, Karaküçük Y. Quantitative analysis of retinal microcirculation in optical coherence tomography angiography in cases with Behçet's disease without ocular involvement. Int Ophthalmol 2019;39:2213-21.

97. Hagag AM, Mitsios A, Gill JS, Nunez Do Rio JM, Theofylaktopoulos V, Houston S, Webster AR, Dubis AM, Moosajee M. Characterisation of microvascular abnormalities using OCT angiography in patients with biallelic variants in USH2A and MYO7A. Br J Ophthalmol 2020;104:480-6.

98. Sacconi R, Casaluci M, Borrelli E, Mulinacci G, Lamanna F, Gelormini F, Carnevali A, Querques L, Zerbini G, Bandello F, Querques G. Multimodal imaging assessment 
of vascular and neurodegenerative retinal alterations in type 1 diabetic patients without fundoscopic signs of diabetic retinopathy. J Clin Med 2019;8:1409.

99. Müller PL, Pfau M, Möller PT, Nadal J, Schmid M, Lindner M, de Sisternes L, Stöhr H, Weber BHF, Neuhaus C, Herrmann P, Schmitz-Valckenberg S, Holz FG, Fleckenstein M. Choroidal flow signal in late-onset stargardt disease and age-related macular degeneration: an OCT-angiography study. Invest Ophthalmol Vis Sci 2018;59:AMD122-31.

100. Conti FF, Qin VL, Rodrigues EB, Sharma S, Rachitskaya AV, Ehlers JP, Singh RP. Choriocapillaris and retinal vascular plexus density of diabetic eyes using splitspectrum amplitude decorrelation spectral-domain optical coherence tomography angiography. Br J Ophthalmol 2019;103:452-6.

101. Keiner CM, Zhou H, Zhang Q, Wang RK, Rinella NT, Oldenburg CE, Duncan JL, Schwartz DM. Quantifying choriocapillaris hypoperfusion in patients with choroidal neovascularization using swept-source OCT angiography. Clin Ophthalmol 2019;13:1613-20.

102. Treister AD, Nesper PL, Fayed AE, Gill MK, Mirza RG, Fawzi AA. Prevalence of subclinical CNV and choriocapillaris nonperfusion in fellow eyes of unilateral exudative AMD on OCT angiography. Transl Vis Sci Technol 2018;7:19.

103. Nassisi M, Baghdasaryan E, Borrelli E, Ip M, Sadda SR. Choriocapillaris flow impairment surrounding geographic atrophy correlates with disease progression. PLoS One 2019;14:e0212563.

104. Conti FF, Song W, Rodrigues EB, Singh RP. Changes in retinal and choriocapillaris density in diabetic patients receiving anti-vascular endothelial growth factor treatment using optical coherence tomography angiography. Int J Retina Vitreous 2019;5:41.

105.Lauermann JL, Heiduschka P, Nelis P, Treder M, Alnawaiseh M, Clemens CR, Eter N, Alten F. Comparison of choriocapillaris flow measurements between two optical coherence tomography angiography devices. Ophthalmologica 2017;237:238-46.

106. Wang Q, Chan S, Yang JY, You B, Wang YX, Jonas JB, Wei WB. Vascular density in retina and choriocapillaris as measured by optical coherence tomography angiography. Am J Ophthalmol 2016;168:95-109.

107. Nassisi M, Baghdasaryan E, Tepelus T, Asanad S, Borrelli E, Sadda SR. Topographic distribution of choriocapillaris flow deficits in healthy eyes. PLoS One 2018;13:e0207638. 108. Demirel S, Değirmenci MFK, Batığlu F, Özmert E.
Evaluation of the choroidal features in pachychoroid spectrum diseases by optical coherence tomography and optical coherence tomography angiography. Eur J Ophthalmol 2019. [Epub ahead of print]. doi: 10.1177/1120672119887095.

109.Lee B, Yoo G, Yun C, Oh J. Short-term effects of antivascular endothelial growth factor on peripapillary choroid and choriocapillaris in eyes with neovascular age-related macular degeneration. Graefes Arch Clin Exp Ophthalmol 2019;257:2163-72.

110. Nassisi M, Shi Y, Fan W, Borrelli E, Uji A, Ip MS, Sadda SR. Choriocapillaris impairment around the atrophic lesions in patients with geographic atrophy: a swept-source optical coherence tomography angiography study. Br J Ophthalmol 2019;103:911-7.

111.Hikichi T, Agarie M. Reduced vessel density of the choriocapillaris during anti-vascular endothelial growth factor therapy for neovascular age-related macular degeneration. Invest Ophthalmol Vis Sci 2019;60:1088-95.

112. Lim CW, Cheng J, Tay ELT, Teo HY, Wong EPY, Yong VKY, Lim BA, Hee OK, Wong HT, Yip LWL. Optical coherence tomography angiography of the macula and optic nerve head: Microvascular density and test-retest repeatability in normal subjects. BMC Ophthalmol 2018;18:315.

113.Hua D, Xu Y, Zeng X, Yang N, Jiang M, Zhang X, Yang J, He T, Xing Y. Use of optical coherence tomography angiography for assessment of microvascular changes in the macula and optic nerve head in hypertensive patients without hypertensive retinopathy. Microvasc Res 2020;129:103969.

114.Liu R, Lu J, Liu Q, Wang Y, Cao D, Wang J, Wang X, Pan J, Ma L, Jin C, Sadda S, Luo Y, Lu L. Effect of choroidal vessel density on the ellipsoid zone and visual function in retinitis pigmentosa using optical coherence tomography angiography. Invest Ophthalmol Vis Sci 2019;60:4328-35.

115. Rochepeau C, Kodjikian L, Garcia MA, Coulon C, Burillon C, Denis P, Delaunay B, Mathis T. Optical coherence tomography angiography quantitative assessment of choriocapillaris blood flow in central serous chorioretinopathy. Am J Ophthalmol 2018;194:26-34.

116.Jain N, Jia Y, Gao SS, Zhang X, Weleber RG, Huang D, Pennesi ME. Optical coherence tomography angiography in choroideremia: Correlating choriocapillaris loss with overlying degeneration. JAMA Ophthalmol 2016;134:697-702.

117. Matet A, Daruich A, Hardy S, Behar-Cohen F. Patterns of Choriocapillaris Flow Signal Voids in Central Serous 
Chorioretinopathy. Retina 2019;39:2178-88.

118. Sacconi R, Borrelli E, Corbelli E, Capone L, Rabiolo A, Carnevali A, Casaluci M, Gelormini F, Querques L, Bandello F, Querques G. Quantitative changes in the ageing choriocapillaris as measured by swept source optical coherence tomography angiography. Br J Ophthalmol 2019;103:1320-6.

119. Karabulut M, Karabulut S, Sül S, Karalezli A. Microvascular changes in amblyopic eyes detected by optical coherence tomography angiography. J AAPOS 2019;23:155.e1-4.

120. Montesano G, Allegrini D, Colombo L, Rossetti LM, Pece A. Features of the normal choriocapillaris with OCTangiography: density estimation and textural properties. PLoS One 2017;12:e0185256.

121.Karaküçük Y, Beyoglu A, Çömez A. Quantitative assessment of the effect of fasting on macular microcirculation: an optical coherence tomography angiography study. Br J Ophthalmol 2020;104:1098-102.

122. Moult EM, Alibhai AY, Rebhun C, Lee B, Ploner S, Schottenhamml J, Husvogt L, Baumal CR, Witkin AJ, Maier A, Duker JS, Rosenfeld PJ, Waheed NK, Fujimoto JG. Spatial distribution of choriocapillaris impairment in eyes with choroidal neovascularization secondary to age-related macular degeneration: a quantitative OCT angiography study. Retina 2020;40:428-45.

123. Spaide RF. Choriocapillaris signal voids in maternally inherited diabetes and deafness and in pseudoxanthoma elasticum. Retina 2017;37:2008-14.

124. Khodabandeh A, Shahraki K, Roohipoor R, RiaziEsfahani H, Yaseri M, Faghihi H, Bazvand F. Quantitative measurement of vascular density and flow using optical coherence tomography angiography (OCTA) in patients with central retinal vein occlusion: can OCTA help in distinguishing ischemic from non-ischemic type? Int J Retina Vitreous 2018;4:47.

125. Moult EM, Alibhai AY, Lee B, Yu Y, Ploner S, Chen S, Maier A, Duker JS, Waheed NK, Fujimoto JG. A framework for multiscale quantitation of relationships between choriocapillaris flow impairment and geographic atrophy growth. Am J Ophthalmol 2020;214:172-87.

126. Kılınç Hekimsoy H, Şekeroğlu MA, Koçer AM, Akdoğan A. Analysis of retinal and choroidal microvasculature in systemic sclerosis: an optical coherence tomography angiography study. Eye (Lond) 2020;34:763-70.

127.Nesper PL, Roberts PK, Onishi AC, Chai H, Liu L, Jampol LM, Fawzi AA. Quantifying microvascular abnormalities with increasing severity of diabetic retinopathy using optical coherence tomography angiography. Invest Ophthalmol Vis Sci 2017;58:BIO307-15.

128. Sugano Y, Sekiryu T, Furuta M, Tomita R, Shintake H, Maehara H, Ojima A. Morphometrical evaluation of the choriocapillaris imaged by swept-source optical coherence tomography angiography. Clin Ophthalmol 2018;12:2267-76.

129. Lee CY, Liu CH, Chen HC, Sun CC, Yao YP, Chao SC. Correlation between basal macular circulation and following glaucomatous damage in progressed hightension and normal-tension glaucoma. Ophthalmic Res 2019;62:46-54.

130. Oh J, Ahn J. Comparison of retinal layer thickness and vascular density between acute and chronic branch retinal vein occlusion. Korean J Ophthalmol 2019;33:238-48.

131. Tzaridis S, Wintergerst MWM, Mai C, Heeren TFC, Holz FG, Charbel Issa P, Herrmann P. Quantification of retinal and choriocapillaris perfusion in different stages of macular telangiectasia type 2. Invest Ophthalmol Vis Sci 2019;60:3556-62.

132. Milani P, Montesano G, Rossetti L, Bergamini F, Pece A. Vessel density, retinal thickness, and choriocapillaris vascular flow in myopic eyes on OCT angiography. Graefes Arch Clin Exp Ophthalmol 2018;256:1419-27. 133. Reich M, Böhringer D, Cakir B, Bucher F, Daniel M, Lang S, Lagrèze W, Agostini H, Lange C. Longitudinal analysis of the choriocapillaris using optical coherence tomography angiography reveals subretinal fluid as a substantial confounder in patients with acute central serous chorioretinopathy. Ophthalmol Ther 2019;8:599-610.

134. Uchida A, Hu M, Babiuch A, Srivastava SK, Singh RP, Kaiser PK, Talcott K, Rachitskaya A, Ehlers JP. Optical coherence tomography angiography characteristics of choroidal neovascularization requiring varied dosing frequencies in treat-and-extend management: an analysis of the AVATAR study. PLoS One 2019;14:e0218889.

135.Mo J, Duan A, Chan S, Wang X, Wei W. Vascular flow density in pathological myopia: an optical coherence tomography angiography study. BMJ Open 2017;7:e013571.

136. Reich M, Glatz A, Cakir B, Böhringer D, Lang S, Küchlin S, Joachimsen L, Lagreze W, Agostini HT, Lange C. Characterisation of vascular changes in different stages of Stargardt disease using double swept-source optical coherence tomography angiography. BMJ Open Ophthalmol 2019;4:e000318.

137.Uji A, Balasubramanian S, Lei J, Baghdasaryan E, 
Al-Sheikh M, Sadda SVR. Choriocapillaris imaging using multiple en face optical coherence tomography angiography image averaging. JAMA Ophthalmol 2017;135:1197-204.

138. Pettenkofer M, Scherm P, Feucht N, Wehrmann K, Lohmann CP, Maier M. Choriocapillaris flow density negatively correlates with advancing age on spectraldomain optical coherence tomography angiography. Ophthalmic Surg Lasers Imaging Retina 2019;50:302-8.

139. Rinella NT, Zhou H, Zhang Q, Keiner C, Oldenburg CE, Duncan JL, Wang RK, Schwartz DM. Quantifying choriocapillaris flow voids in patients with geographic atrophy using swept-source OCT angiography. Ophthalmic Surg Lasers Imaging Retina 2019;50:e229-35. 140. Yun C, Huh J, Ahn SM, Lee B, Kim JT, Hwang SY, Kim SW, Oh J. Choriocapillaris flow features and choroidal vasculature in the fellow eyes of patients with acute central serous chorioretinopathy. Graefes Arch Clin Exp Ophthalmol 2019;257:57-70.

141. Rispoli M, Savastano MC, Lumbroso B. Quantitative vascular density changes in choriocapillaris around $\mathrm{CNV}$ after anti-VEGF treatment: Dark Halo. Ophthalmic Surg Lasers Imaging Retina 2018;49:918-24.

142. Mastropasqua R, Toto L, Di Antonio L, Borrelli E, Senatore A, Di Nicola M, Di Martino G, Ciancaglini M, Carpineto P. Optical coherence tomography angiography microvascular findings in macular edema due to central and branch retinal vein occlusions. Sci Rep 2017;7:40763.

143. Shin YU, Lee DE, Kang MH, Seong M, Yi JH, Han SW, Cho H. Optical coherence tomography angiography analysis of changes in the retina and the choroid after haemodialysis. Sci Rep 2018;8:17184.

144. Sarwar S, Hassan M, Soliman MK, Halim MS, Sadiq MA, Afridi R, Agarwal A, Do DV, Nguyen QD, Sepah YJ. Diurnal variation of choriocapillaris vessel flow density in normal subjects measured using optical coherence tomography angiography. Int J Retina Vitreous 2018;4:37.

145. Thulliez M, Zhang Q, Shi Y, Zhou H, Chu Z, de Sisternes L, Durbin MK, Feuer W, Gregori G, Wang RK, Rosenfeld PJ. Correlations between choriocapillaris flow deficits around geographic atrophy and enlargement rates based on swept-source OCT imaging. Ophthalmol Retina 2019;3:478-88.

146. Scherm P, Pettenkofer M, Maier M, Lohmann CP, Feucht N. Choriocapillary blood flow in myopic subjects measured with OCT angiography. Ophthalmic Surg Lasers Imaging Retina 2019;50:e133-9.

147.Vujosevic S, Martini F, Longhin E, Convento
E, Cavarzeran F, Midena E. Optical coherence tomography angiography changes after subthreshold micropulse yellow laser in diabetic macular edema. Retina 2018. [Epub ahead of print]. doi: 10.1097/ IAE.0000000000002383.

148. Takayama K, Kaneko H, Ito Y, Kataoka K, Iwase T, Yasuma T, Matsuura T, Tsunekawa T, Shimizu H, Suzumura A, Ra E, Akahori T, Terasaki H. Novel classification of earlystage systemic hypertensive changes in human retina based on OCTA measurement of choriocapillaris. Sci Rep 2018;8:15163.

149. Vujosevic S, Toma C, Villani E, Muraca A, Torti E, Florimbi G, Leporati F, Brambilla M, Nucci P, De Cilla'

S. Diabetic macular edema with neuroretinal detachment: OCT and OCT-angiography biomarkers of treatment response to anti-VEGF and steroids. Acta Diabetol 2020;57:287-96.

150. Teng Y, Yu M, Wang Y, Liu X, You Q, Liu W. OCT angiography quantifying choriocapillary circulation in idiopathic macular hole before and after surgery. Graefes Arch Clin Exp Ophthalmol 2017;255:893-902.

151.Vujosevic S, Toma C, Villani E, Muraca A, Torti E, Florimbi G, Pezzotti M, Nucci P, De Cillà S. Quantitative choriocapillaris evaluation in intermediate age-related macular degeneration by swept-source optical coherence tomography angiography. Acta Ophthalmol 2019;97:e919-26.

152. Toto L, D'Aloisio R, Di Nicola M, Di Martino G, Di Staso S, Ciancaglini M, Tognetto D, Mastropasqua L. Qualitative and quantitative assessment of vascular changes in diabetic macular edema after dexamethasone implant using optical coherence tomography angiography. Int J Mol Sci 2017;18:1181.

153. Yip VCH, Wong HT, Yong VKY, Lim BA, Hee OK, Cheng J, Fu H, Lim C, Tay ELT, Loo-Valdez RG, Teo HY, Lim Ph A, Yip LWL. Optical coherence tomography angiography of optic disc and macula vessel density in glaucoma and healthy eyes. J Glaucoma 2019;28:80-7.

154. Tsai G, Banaee T, Conti FF, Singh RP. Optical coherence tomography angiography in eyes with retinal vein occlusion. J Ophthalmic Vis Res 2018;13:315-32.

155. Tsen CL, Sheu SJ, Chen SC, Wu TT. Imaging analysis with optical coherence tomography angiography after primary repair of macula-off rhegmatogenous retinal detachment. Graefes Arch Clin Exp Ophthalmol 2019;257:1847-55.

156. Urfalıoglu S, Bakacak M, Özdemir G, Güler M, Beyoglu A, Arslan G. Posterior ocular blood flow in preeclamptic 
patients evaluated with optical coherence tomography angiography. Pregnancy Hypertens 2019;17:203-8.

157.Zhang Y, Weng H, Li Q, Wang Z. Changes in retina and choroid after haemodialysis assessed using optical coherence tomography angiography. Clin Exp Optom 2018;101:674-9.

158. Wang J, Jiang J, Zhang Y, Qian YW, Zhang JF, Wang ZL. Retinal and choroidal vascular changes in coronary heart disease: an optical coherence tomography angiography study. Biomed Opt Express 2019;10:1532-44.

159.Wang SW, Hung KC, Tsai CY, Chen MS, Ho TC. Myopic traction maculopathy biomarkers on optical coherence tomography angiography—an overlooked mechanism of visual acuity correction in myopic eyes. Eye 2019;33:1305-13.

160. Yang J, Wang E, Zhao X, Xia S, Yuan M, Chen H, Zhang $\mathrm{X}$, Chen Y. Optical coherence tomography angiography analysis of the choriocapillary layer in treatment-naïve diabetic eyes. Graefes Arch Clin Exp Ophthalmol 2019;257:1393-9.

161.Zhang Z, Huang X, Meng X, Chen T, Gu Y, Wu Y, Wu $Z$. In vivo assessment of macula in eyes of healthy children 8 to 16 years old using optical coherence tomography angiography. Sci Rep 2017;7:8936. 